\title{
Effects of Phytoestrogens on Acetylcholine- and Isoprenaline-Induced Vasodilation in Rat Aorta
}

\author{
Kiyoshi Yamaguchi, Hideo Honda, Chiaki Wakisaka, Atsushi Tohei and Hiroshi Kogo* \\ Department of Pharmacology, Tokyo University of Pharmacy and Life Science, 1432-1, Horinouchi, Hachioji, Tokyo 192-0392, Japan
}

Received May 9, 2001 Accepted June 28, 2001

\begin{abstract}
The influence of the phytoestrogen, isoflavones, on vasodilating responses of the thoracic aorta precontracted with norepinephrine, together with the stimulatory effect on uterine weight (uterotrophic effect), was investigated in ovariectomized rats. In comparison with intact rats, acetylcholine (ACh)-induced vasodilation showed a tendency to be decreased by ovariectomy. On the other hand, isoprenaline (ISO)induced vasodilation was significantly increased by ovariectomy. Estrogen replacement (17 $\beta$-estradiol dipropionate, $300 \mu \mathrm{g} / \mathrm{kg}$ per week, for 1 month) completely restored the impaired ACh- and ISO-induced vasodilation caused by ovariectomy. Dietary isoflavone aglycones (containing $52 \%$ genistein, $42 \%$ daidzein and $6 \%$ glycitein) of $157 \mathrm{mg} / \mathrm{kg}$ per day (not $67 \mathrm{mg} / \mathrm{kg}$ per day) for 1 month, in addition to the effects of estrogen replacement, completely restored the impaired vasodilation caused by ovariectomy. However, the uterotrophic effect of dietary isoflavones of $157 \mathrm{mg} / \mathrm{kg}$ per day was incomplete as compared with that by estrogen replacement. These results indicate that phytoestrogen, isoflavones, certainly possess estrogenic actions on the vasodilating responses caused by ACh and ISO, as well as a weaker uterotrophic effect.
\end{abstract}

Keywords: Isoflavones (genistein and daidzein), Estradiol, Acetylcholine, Isoprenaline, Rat aorta

After menopause, the risk for cardiovascular diseases is promoted by some metabolic and vascular changes, which may be partly due to estrogen deficiency. There are many reports that estrogen replacement therapy reduces cardiovascular disease mortality in post-menopausal women $(1,2)$. Evidence for the influences of estrogen on cardiovascular diseases is partly derived from the alterations in vascular reactivity. High levels of circulating estrogen have been reported to modulate the vasoactive reagentsinduced responses. Acetylcholine ( $\mathrm{ACh}$ )-induced endothelium-dependent vasodilations are increased during the late stage of pregnancy in guinea pig mesenteric artery (3) and rat aorta (4), and it has also been found in $17 \beta$-estradiol $\left(E_{2}\right)$-treated rat aorta (5) or rabbit femoral artery (6). Furthermore, we have reported that the relaxing response to isoprenaline (ISO) was suppressed by a short-term treatment with $E_{2}$ in rat aorta (7). These evidences indicate that the agonists-induced vasodilation is certainly affected by endogenous or exogenous estrogens.

It is known that phytoestrogens with nonsteroidal structures such as isoflavones are naturally-occurring plant compounds, which bind to estrogen receptor (ER) and

*Corresponding author. FAX: +81-426-76-4526

E-mail: kogo@ps.toyaku.ac.jp exhibit weak estrogen-like biological activity (8). The isoflavones, genistein and daidzein, are present in high concentrations in soybean products (9). Recently, their components in phytoestrogens are believed to be important for the prevention of cardiovascular diseases, reproductive cancers and osteoporosis $(8,10,11)$. In the vasoprotective actions of phytoestrogens, a study of cholesterol-fed rabbits showed that isoflavone aglycone attenuates atherosclerosis development by inhibiting the oxidation of low density lipoprotein (12). Furthermore, a soy diet enhanced the dilating response induced by $\mathrm{ACh}$ in atherosclerotic coronary arteries of female rhesus monkeys (13). Genistein supplement improved the endothelial dysfunction induced by ovariectomy in rats through increased nitric oxide synthase (NOS) activity (14). These effects of phytoestrogens mimicking the actions of endogenous estrogen may contribute to their vasoprotective effects.

ER has been reported to exist as two subtypes, the "classical" estrogen receptor $\mathrm{ER} \alpha$ and the novel $\mathrm{ER} \beta$, in rat aorta (15) and other tissues (16). The physiological roles of each ER are not clear at present, but the uterus clearly expressed the messenger RNAs (mRNAs) of both ER subtypes, and the predominant ER subtype in the uterus was $\operatorname{ER} \alpha(16)$. Mäkelä et al. demonstrated that the expression of $\mathrm{ER} \beta$ mRNA increased after endothelial denudation 
of carotid artery in female rats (17). Genistein showed 20 -fold higher binding affinity to $\operatorname{ER} \beta$ than to $\operatorname{ER} \alpha$ (18). Furthermore, isoflavones in soy protein improved cardiovascular risk factors without deleterious effects on the reproductive system of monkeys (19). These results suggest that $\operatorname{ER} \beta$ plays a pivotal role in vasoprotection and that phytoestrogen, isoflavones, may be valuable compounds for estrogen-based drug therapy for cardiovascular diseases. However, it is not clear whether isoflavones exhibit estrogen-like actions on the relaxing responses to $\mathrm{ACh}$ and/or ISO and whether they accompany modulated vascular responses with a risk of affecting the reproductive system.

With these experimental backgrounds, we examined whether or not phytoestrogens have estrogen-like actions on the vascular reactivity of ACh and ISO and the uterine weight.

\section{MATRIALS AND METHODS}

\section{Animals and treatment with estrogen}

All procedures were carried out in accordance with the institutional guidelines for animal research of Tokyo University of Pharmacy and Life Science. Female WistarImamichi strain rats $(150-180 \mathrm{~g})$ were purchased from the Institute for Animal Reproduction (Ibaraki). Rats were divided into 5 groups: 1) Estrous intact rats, 2) Ovariectomized (OVX) rats, 3) OVX rats with estrogen replacement, 4) and 5) OVX rats with different doses of isoflavones supplement. After ovariectomy, the rats were immediately injected with $17 \beta$-estradiol dipropionate (EDP) (300 $\mu \mathrm{g}$ $/ \mathrm{kg}$, s.c.). Then the rats were injected with it once a week for 3 weeks (totally 4 times in 4 weeks), and the samples were isolated 1 week after the final injection.

\section{Isoflavones and diet}

The isoflavone aglycones in SoyAct ${ }^{\mathrm{TM}}$, which was provided by Kikkoman Corporation (Chiba), consist of $52 \%$ genistein, $42 \%$ daidzein and $6 \%$ glycitein. The OVX rats orally received a diet containing SoyAct ${ }^{\mathrm{TM}}$. The rats were fed with isoflavone aglycones of $67 \mathrm{mg} / \mathrm{kg}$ body weight (BW) per day or $157 \mathrm{mg} / \mathrm{kg} \mathrm{BW}$ per day for 1 month. The rats fed with $67 \mathrm{mg} / \mathrm{kg} \mathrm{BW}$ per day and $157 \mathrm{mg} / \mathrm{kg}$ BW per day were designated as groups I-67 and I-157, respectively. In our preliminary study, we chose two doses of isoflavone aglycones; a lower dose had no influence on uterine weight and a higher dose increased it.

\section{Preparation of aorta}

All animals were anesthetized with ether and euthanatized by exsanguination. Blood samples were collected from the femoral artery and the serum was frozen $\left(-80^{\circ} \mathrm{C}\right)$ for analyzing the $\mathrm{E}_{2}$ levels. The thoracic aortae were isolated and cleaned of the adherent fat and connective tissue in modified Krebs-Henseleit solution of the following composition: $118 \mathrm{mM} \mathrm{NaCl}, 4.7 \mathrm{mM} \mathrm{KCl}, 2.5 \mathrm{mM} \mathrm{CaCl}_{2}$, $1.2 \mathrm{mM} \mathrm{MgSO}_{4}, 1.2 \mathrm{mM} \mathrm{KH} \mathrm{PO}_{4}, 25 \mathrm{mM} \mathrm{NaHCO}$ and $11 \mathrm{mM}$ glucose at $37^{\circ} \mathrm{C}$, gassed with $95 \% \mathrm{O}_{2}$ and $5 \%$ $\mathrm{CO}_{2}$. The aortic preparations were cut into rings of about 5-mm-long, and 5 ring preparations were obtained from each animal.

\section{Measurement of isometric tension}

The relaxing responses were measured by suspending the rings between two stainless-steel hooks, one of which was attached to the end of a bathing tube and the other to a force transducer (45196A; NEC San-ei Instruments, Inc., Tokyo). The isometric tension changes were recorded on a polygraph (LECT-HORIZ-8K; NEC San-ei Instruments, Inc.). The resting tension was $0.8 \mathrm{~g}$, which was the optimal preload for force development in these blood vessels, as previously described (20). For the relaxing response studies, the submaximal tone was induced with $6 \times 10^{-7} \mathrm{M}$ norepinephrine (NE) and then $\mathrm{ACh}$ or ISO was added in a cumulative fashion. Relaxation in response to them was expressed as the percent decrease from the NE-induced tension.

\section{Radioimmunoassay (RIA)}

Levels of $E_{2}$ in peripheral serum were determined by double-antibody RIA systems using ${ }^{125} \mathrm{I}$ labeled radioligands. The labeled steroid was oestradiol-6-(O-carboxymethyl) oximino-2-[ $\left.{ }^{125} \mathrm{I}\right]$ iodohistamine (IM135), which was purchased from Amersham Pharmacia Biotech (Tokyo). Antisera against $\mathrm{E}_{2}$ (GDN 244) were used (21). The RIA techniques used for determination of $\mathrm{E}_{2}$ were the same as the procedures previously described (22). The intra- and inter-assay coefficients of variation were 6.2 and $7.4 \%$ for $\mathrm{E}_{2}$, respectively.

\section{Drugs}

Norepinephrine bitartrate, isoprenaline bitartrate, sodium nitroprusside dihydrate (Sigma Chemical Co., St. Louis, MO, USA) and acetylcholine chloride (Daiichi Pharmaceutical Co., Tokyo) were dissolved in distilled water. $17 \beta$-Estradiol dipropionate (Sigma) was dissolved in sesame oil (Miyazawa, Tokyo). Genistein was obtained from the Laboratory of Medical Plant Science, Tokyo University of Pharmacy and Life Science. The other chemicals were of analytical grade and obtained from Wako Pure Chemical Co. (Osaka).

\section{Data analyses}

Values were expressed as the mean \pm S.E.M. When the dose-response curves were compared among the groups, the statistical significance was assessed by an analysis of variance (ANOVA) for repeated measures followed by 
the Tukey test. The differences were considered significant for $P<0.05$.

\section{RESULTS}

Comparisons of isoflavones and estrogen supplement for physiological characteristics

In OVX rats, the growth rate was larger than that of intact rats, but EDP or I-157 supplement to OVX rats markedly inhibited the increased growth rate. Changes in the increased body weight depended on food consumption. EDP or I-157 (not I-67) supplement to OVX rats increased uterine wet weight per animal, and EDP completely restored the uterine weight to the levels in intact rats. No significant differences were seen in the levels of serum $E_{2}$ between isoflavones-treated OVX rats (I-67 or I-157) and OVX rats (Table 1). The concentrations in EDP-treated OVX rats were similar to those in proestrous rats $(54.8$ $\pm 3.4 \mathrm{pg} / \mathrm{ml})$.

Effects of isoflavones and estrogen supplement on AChinduced vasodilation in OVX rats

In this study, the tensions induced by NE $\left(6 \times 10^{-7} \mathrm{M}\right)$ were $155 \pm 8$ and $114 \pm 8 \mathrm{mg}$ in intact and OVX rat aortic rings, respectively $(P<0.01)$. The tensions induced by NE were $137 \pm 11$ and $116 \pm 8 \mathrm{mg}$ in I-67- and I-157-treated OVX rat aortic rings, respectively. In agreement with Miller and Vanhoutte (23), the NE-induced contraction in EDP-treated OVX rats $(151 \pm 8 \mathrm{mg})$ was greater than that in OVX rats $(P<0.05)$.

The endothelium-dependent vasodilation by ACh $\left(10^{-9}-\right.$ $3 \times 10^{-6} \mathrm{M}$ ) showed a tendency to decrease in OVX rats, compared with the response in intact rats, although it was not significant. Supplement with EDP (Fig. 1A, Table 2) and I-157 (Fig. 1B, Table 2) restored the decreased vasodilating response induced by ovariectomy to the levels in

Table 1. Physiological characteristics in isoflavones and estrogen supplement

\begin{tabular}{lcccc}
\hline Groups & GR $(\mathrm{g})$ & $\mathrm{FC}(\mathrm{g} /$ day $)$ & $\mathrm{UW}(\mathrm{mg} /$ animal $)$ & $\mathrm{Serum} \mathrm{E}_{2}(\mathrm{pg} / \mathrm{ml})$ \\
\hline Intact & $60 \pm 4^{* *}$ & $14 \pm 0.2$ & $420 \pm 39^{* *}$ & $19.6 \pm 2.6$ \\
OVX & $103 \pm 5$ & $16 \pm 0.7$ & $112 \pm 23$ & $19.3 \pm 2.0$ \\
OVX + EDP & $37 \pm 4^{* *}$ & $12 \pm 0.4^{* *}$ & $417 \pm 37^{* *}$ & $67.1 \pm 14.6^{* *}$ \\
OVX + I-67 & $88 \pm 5$ & $15 \pm 0.8$ & $130 \pm 10$ & $14.9 \pm 3.5$ \\
OVX + I-157 & $43 \pm 6^{* *}$ & $12 \pm 0.4^{* *}$ & $317 \pm 32^{* *}$ & $13.7 \pm 1.7$ \\
\hline
\end{tabular}

OVX rats were subcutaneously injected with EDP (300 $\mu \mathrm{g} / \mathrm{kg}$ per week) for 1 month. OVX rats were fed with $67 \mathrm{mg} / \mathrm{kg}$ per day or $157 \mathrm{mg} / \mathrm{kg}$ per day of isoflavones for 1 month. They were defined as I-67 and I-157, respectively. GR: growth rate, FC: food consumption, UW: uterine wet weight. Each value represents the mean \pm S.E.M. from 5 to 10 rats. $* * P<0.01$, from OVX.

(A)

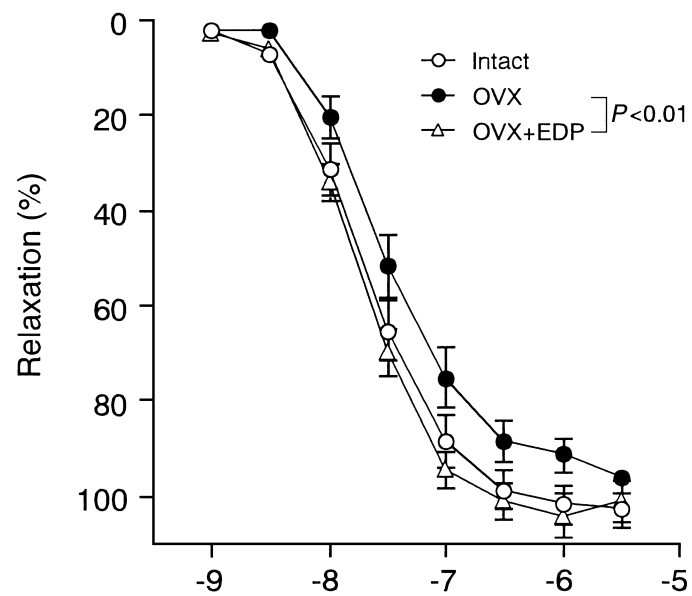

(B)

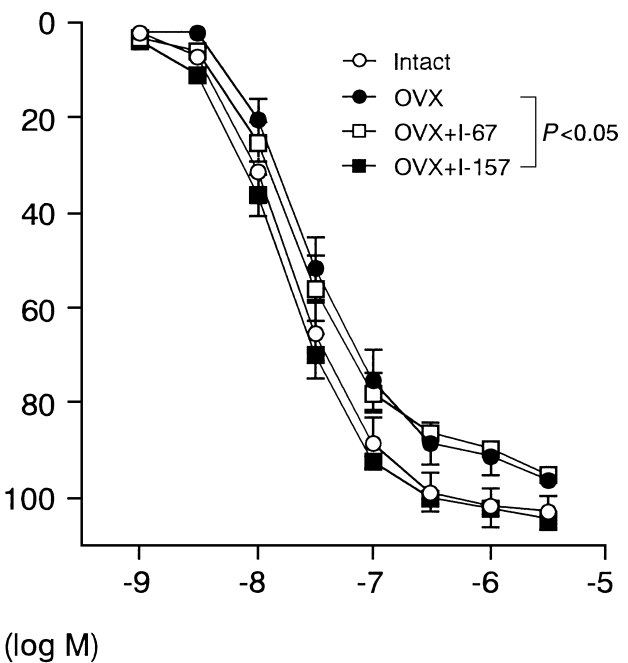

Fig. 1. Effects of EDP (A) and isoflavones (B) on ACh-induced vasodilation in aortic rings from OVX rats. OVX rats were subcutaneously injected with EDP $(300 \mu \mathrm{g} / \mathrm{kg}$ per week) for 1 month. OVX rats were fed with $67 \mathrm{mg} / \mathrm{kg}$ per day or $157 \mathrm{mg}$ $/ \mathrm{kg}$ per day of isoflavones for 1 month. They were defined as I-67 and I-157, respectively. Each value represents the mean \pm S.E.M. from 6 to 10 rats. 
Table 2. $\mathrm{EC}_{50}$ and $\mathrm{E}_{\max }$ to $\mathrm{ACh}$ and $\mathrm{ISO}$ in isoflavones and estrogen supplement

\begin{tabular}{lccccc}
\hline \multirow{2}{*}{ Groups } & \multicolumn{2}{c}{$\mathrm{EC}_{50}$} & & \multicolumn{2}{c}{$\mathrm{E}_{\max }$} \\
\cline { 2 - 3 } \cline { 5 - 6 } Intact & $\mathrm{ACh}$ & $\mathrm{ISO}$ & & $\mathrm{ACh}$ & ISO \\
OVX & $7.64 \pm 0.09$ & $7.74 \pm 0.06$ & & $98.1 \pm 1.7$ & $71.7 \pm 2.1^{* *}$ \\
OVX + EDP & $7.48 \pm 0.10$ & $7.75 \pm 0.04$ & & $96.9 \pm 2.5$ & $81.5 \pm 2.2$ \\
OVX + I-67 & $7.74 \pm 0.06^{*}$ & $7.70 \pm 0.06$ & & $99.6 \pm 3.5$ & $74.0 \pm 2.4^{*}$ \\
OVX + I-157 & $7.61 \pm 0.09$ & $7.65 \pm 0.06$ & & $95.3 \pm 2.2$ & $83.5 \pm 2.6$ \\
\hline
\end{tabular}

$\mathrm{EC}_{50}$ are expressed as $\mathrm{pD}_{2}$ values, maximal relaxation $\left(\mathrm{E}_{\max }\right)$ are expressed as percent precontraction with NE. Each value represents the mean \pm S.E.M. from 6 to 10 rats. ${ }^{*} P<0.05, * * P<0.01$, from OVX.

intact rats, but I-67 had no influence on it. Both the values of $\mathrm{EC}_{50}$ and the maximal relaxation were significantly increased in I-157-treated OVX rats compared with OVX rats (Table 2). In an additional study, we investigated the effects of a short-term treatment with genistein $(10 \mathrm{mg} / \mathrm{kg}$ per day, s.c., for 1 week) on ACh-induced vasodilation using OVX rats. The effects of genistein treatment on AChinduced vasodilation were not observed (data not shown).

Effects of isoflavones and estrogen supplement on ISOinduced vasodilation in OVX rats

ISO-induced vasodilation $\left(10^{-9}-3 \times 10^{-6} \mathrm{M}\right)$ was significantly increased by ovariectomy, compared with that in intact rats, and EDP supplement to OVX rats completely restored the increased vasodilating response induced by ovariectomy to the levels in intact rats (Fig. 2A, Table 2). I-157 supplement also completely restored it to those in intact rats. However, I-67 supplement did not affect ISO- induced vasodilation, compared with the response in OVX rats (Fig. 2B, Table 2). The effects of a short-term treatment with genistein on ISO-induced vasodilation were not observed, either (data not shown).

\section{DISCUSSION}

In the present study, we used OVX rats to investigate pure actions of phytoestrogens on vasodilating responses and uterotrophic effects without the modulation of endogenous ovarian hormones, because it has been reported that the consumption of soymilk containing $>200 \mathrm{mg}$ of isoflavones daily for 1 month effectively reduced the circulating levels of $E_{2}$ and increased menstrual cycle length in premenopausal women (24). Dietary I-67 and I-157 did not change the levels of serum $\mathrm{E}_{2}$, compared with those in OVX rats. There was no significant difference in the levels of serum $E_{2}$ between estrous and OVX rats, suggesting that
(A)

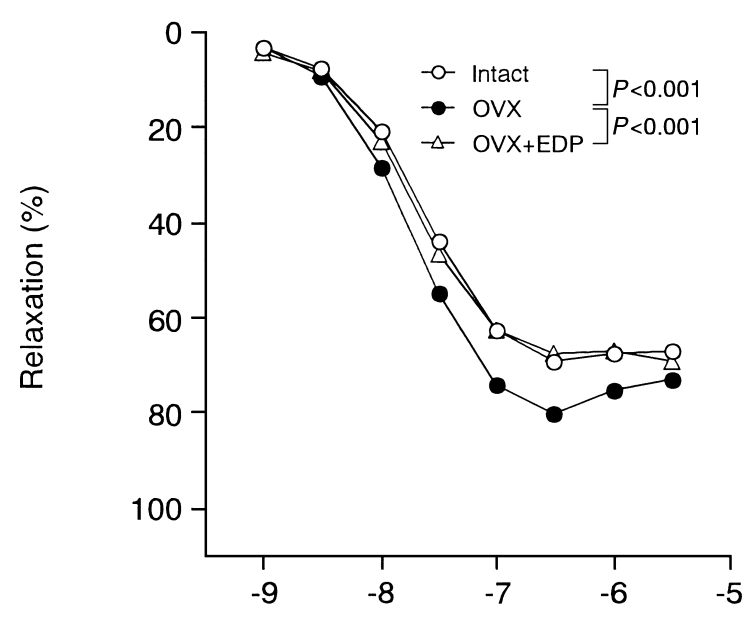

(B)

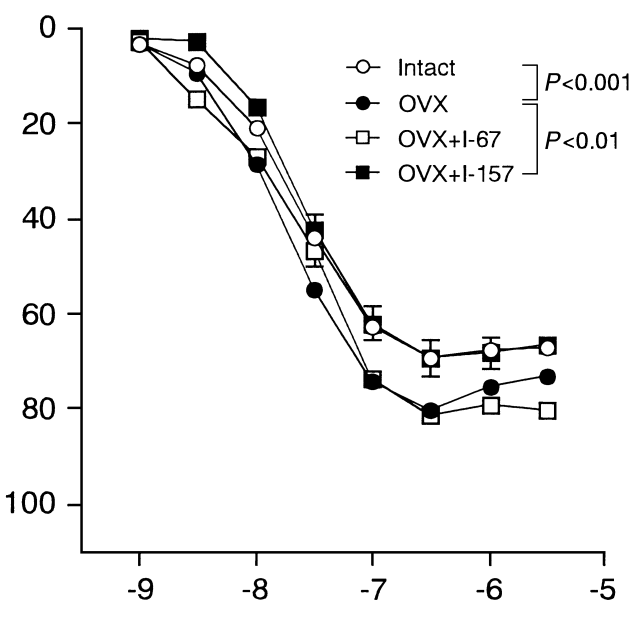

ISO $(\log M)$

Fig. 2. Effects of EDP (A) and isoflavones (B) on ISO-induced vasodilation in aortic rings from OVX rats. OVX rats were subcutaneously injected with EDP (300 $\mu \mathrm{g} / \mathrm{kg}$ per week) for 1 month. OVX rats were fed with $67 \mathrm{mg} / \mathrm{kg}$ per day or $157 \mathrm{mg}$ $/ \mathrm{kg}$ per day of isoflavones for 1 month. They were defined as I-67 and I-157, respectively. Each value represents the mean \pm S.E.M. from 6 to 10 rats. 
both of these $E_{2}$ levels were derived from the adrenal gland. Supplement with EDP and a high dose of isoflavones, I157 , exhibited a stimulatory effect on uterine weight, and the potency of I-157 was less than that of EDP supplement. On the other hand, I-67 did not show any uterotrophic effect at all. The effects of supplement with EDP and I-157 were the same on the growth rate and food consumption. Based on these physiological characteristics of phytoestrogens, we investigated their influence on the endotheliumdependent vasodilation in isolated aortic preparations. ACh-induced vasodilation was somewhat decreased in 4 weeks after ovariectomy, but ISO-induced vasodilation was significantly increased. Estrogen replacement by EDP supplement completely restored these modulated vasodilating responses. Although these opposite effects of ACh- and ISO-induced vasodilation induced by ovariectomy are not clear, it is suggested that ovarian steroid hormones may be associated with the regulation of vascular tone $(2,25,26)$. High-dose isoflavones, I-157, also completely restored these modulated vascular responses, but not I-67, meaning that high-dose isoflavones, which have a sufficient stimulatory effect on uterine weight, exhibit estrogenic actions on ACh- and ISO-induced vasodilation. However, the uterotrophic effect of I-157 was less than that of EDP supplement. These results suggest that phytoestrogens may exert a greater influence on the vascular system than on the reproductive system. This specificity of isoflavones may be explained by the expression levels of ER subtypes in different tissues and by the binding affinity of phytoestrogens to ER subtypes. That is, genistein shows a higher binding affinity to $\operatorname{ER} \beta$ than to $\mathrm{ER} \alpha$, while $\mathrm{E}_{2}$ does not differentiate between the two receptors (18). The ER $\alpha$ mRNA is highly expressed in the uterus (16). The present study is the first observation showing that actions of phytoestrogens affect the regulation of vascular tone rather than uterotrophic effects.

The mechanisms for the vasodilating response to $\mathrm{ACh}$ increased by estrogen have been suggested to be mainly associated with an increase in NO release stimulated by $\mathrm{ACh}(25,27)$. It has been reported that $\mathrm{E}_{2}$ rapidly stimulates NOS activity in endothelial cells in a nongenomic manner, and the activation is antagonized by ER antagonists such as tamoxifen and ICI 182,780 $(28,29)$. Recently, genistein has also been suggested to cause acute NO-dependent vasodilation in the forearm vasculature of human subjects with a similar potency to $\mathrm{E}_{2}(30)$. However, a long-term treatment with estrogen induces the expression of some target genes (including NOS) $(29,31)$. In the present study, the modulation induced by treatment with estrogen including phytoestrogens for 1 month in ACh-induced vasodilation may not be contributable to its rapid actions. The endothelium-independent vasodilation by sodium nitroprusside was hardly affected by ovariectomy and/or addi- tional EDP or isoflavones $\left(\mathrm{EC}_{50}\right.$ : Intact, $8.02 \pm 0.05$; OVX, $7.91 \pm 0.07 ;$ OVX + EDP, $7.95 \pm 0.05 ;$ OVX + I-67, 8.05 \pm 0.04 ; OVX $+\mathrm{I}-157,7.94 \pm 0.08$ ), suggesting that estrogen does not alter the sensitivity of vascular smooth muscle to exogenous NO.

The mechanism for the relationship between $\beta$-adrenoceptor-mediated vasodilation and estrogen is not clear. However, it has been reported that isoprenaline-induced vasodilation of rat aorta may involve the cytochrome $\mathrm{P} 450$ (CYP) pathway $(7,32)$. We have also observed that the levels of CYP2C11 mRNA expression in rat aorta were modulated by estrogen (K. Yamaguchi et al., unpublished data). It has been reported that the members of the CYP2C gene family synthesize both epoxyeicosatrienoic acids and 20-hydroxyeicosatetraenoic acid from arachidonic acid $(33,34)$. Indeed, those CYP2C-derived products cause the vasodilating (35) and contractile response (36), respectively. The mechanisms for the vasodilating response to ISO decreased by estrogen may be partly associated with an alteration in the amounts of CYP2C-derived products. Furthermore, we have observed that the actions of $\mathrm{E}_{2}$ on ISO-induced vasodilation were almost antagonized by ICI 182,780 (K. Yamaguchi et al., unpublished data). Therefore, ER may mediate the decrease in $\beta$-adrenoceptormediated vasodilation by estrogen and phytoestrogens.

Furthermore, we studied the effects of a short-term treatment with genistein on the vascular system and the reproductive system. Administration of genistein $(10 \mathrm{mg} / \mathrm{kg}$ per day, s.c.) for 1 week to OVX rats exhibited a slight uterotrophic effect (OVX: $100 \pm 2 \mathrm{mg}$ vs OVX + genistein: $136 \pm 12 \mathrm{mg}, \mathrm{n}=4, P<0.05)$. However, there was no significant difference in ACh- and ISO-induced vasodilation between OVX rats and genistein-treated OVX rats (data not shown). Therefore, in order to observe the influence of estrogenic effects on vasodilating responses, phytoestrogens may need to be administered over a long period of time.

Our findings indicate that phytoestrogens certainly possess estrogenic actions on the vasodilating responses to ACh and ISO and exhibit a higher sensitivity for the vascular system than the reproductive system. These results suggest that the estrogenic effects of isoflavones on vasodilating responses may contribute to one of their vasoprotective actions.

\section{Acknowledgments}

We thank Kikkoman Corporation for providing SoyAct ${ }^{\mathrm{TM}}$, Prof. Yutaka Sashida and Dr. Yoshihiro Mimaki of Tokyo University of Pharmacy and Life Science for providing genistein, and Prof. Seiichi Saida of Tokyo University of Pharmacy and Life Science for a critical reading of the manuscript. This study was partly supported by the Sasakawa Scientific Research Grant from The Japan Science Society and the US-Japan Cooperative Research Grant from the Japan Society for Promotion of Science. 


\section{REFERENCES}

1 Nabulsi AA, Folsom AR, White A, Patsch W, Heiss G, Wu KK and Szklo M: Association of hormone-replacement therapy with various cardiovascular risk factors in postmenopausal women. The Atherosclerosis Risk in Communities Study Investigators. N Engl J Med 328, 1069 - 1075 (1993)

2 Skafar DF, Xu R, Morales J, Ram J and Sowers JR: Clinical review 91: Female sex hormones and cardiovascular disease in women. J Clin Endocrinol Metab 82, 3913 - 3918 (1997)

3 Kim TH, Weiner CP and Thompson LP: Effect of pregnancy on contraction and endothelium-mediated relaxation of renal and mesenteric arteries. Am J Physiol 267, H41 - H47 (1994)

4 Honda H, Kaneko H, Kondo M and Kogo H: Comparison of endothelium-derived relaxing factor activity between nonpregnant and pregnant rats. Comp Biochem Physiol 114, $193-$ 196 (1996)

5 Cheng DY, Feng CJ, Kadowitz PJ and Gruetter CA: Effects of $17 \beta$-estradiol on endothelium-dependent relaxation induced by acetylcholine in female rat aorta. Life Sci 55, PL187 - PL191 (1994)

6 Gisclard V, Miller VM and Vanhoutte PM: Effect of $17 \beta$ estradiol on endothelium-dependent responses in the rabbit. J Pharmacol Exp Ther 244, 19 - 22 (1988)

7 Honda H, Yamaguchi $\mathrm{K}$ and Kogo H: $17 \beta$-Estradiol alters isoproterenol-induced relaxation in rat aortic rings. Jpn $\mathrm{J}$ Pharmacol 77, 311 - 313 (1998)

8 Murkies AL, Wilcox G and Davis SR: Clinical review 92: Phytoestrogens. J Clin Endocrinol Metab 83, 297 - 303 (1998)

9 Price KR and Fenwick GR: Naturally occurring oestrogens in foods - a review. Food Addit Contam 2, 73 - 106 (1985)

10 Ishimi Y, Miyaura C, Ohmura M, Onoe Y, Sato T, Uchiyama Y, Ito $\mathrm{M}$, Wang $\mathrm{X}$, Suda $\mathrm{T}$ and Ikegami S: Selective effects of genistein, a soybean isoflavone, on B-lymphopoiesis and bone loss caused by estrogen deficiency. Endocrinology 140, $1893-$ 1900 (1999)

11 Cassidy A and Griffin B: Phyto-oestrogens: a potential role in the prevention of CHD? Proc Nutr Soc 58, 193 - 199 (1999)

12 Yamakoshi J, Piskula MK, Izumi T, Tobe K, Saito M, Kataoka S, Obata A and Kikuchi M: Isoflavone aglycone-rich extract without soy protein attenuates atherosclerosis development in cholesterol-fed rabbits. J Nutr 130, 1887 - 1893 (2000)

13 Honore EK, Williams JK, Anthony MS and Clarkson TB: Soy isoflavones enhance coronary vascular reactivity in atherosclerotic female macaques. Fertil Steril 67, 148 - 154 (1997)

14 Squadrito F, Altavilla D, Squadrito G, Saitta A, Cucinotta D, Minutoli L, Deodato B, Ferlito M, Campo GM, Bova A and Caputi AP: Genistein supplementation and estrogen replacement therapy improve endothelial dysfunction induced by ovariectomy in rats. Cardiovasc Res 45, $454-462$ (2000)

15 Lindner V, Kim SK, Karas RH, Kuiper GG, Gustafsson JA and Mendelsohn ME: Increased expression of estrogen receptor- $\beta$ mRNA in male blood vessels after vascular injury. Circ Res 83, $224-229$ (1998)

16 Kuiper GG, Carlsson B, Grandien K, Enmark E, Haggblad J, Nilsson S and Gustafsson JA: Comparison of the ligand binding specificity and transcript tissue distribution of estrogen receptors $\alpha$ and $\beta$. Endocrinology 138, 863 - 870 (1997)

17 Mäkelä S, Savolainen H, Aavik E, Myllärniemi M, Strauss L, Taskinen E, Gustafsson JA and Häyry P: Differentiation between vasculoprotective and uterotrophic effects of ligands with different binding affinities to estrogen receptors $\alpha$ and $\beta$. Proc Natl Acad Sci USA 96, 7077 - 7082 (1999)

18 Kuiper GG, Lemmen JG, Carlsson B, Corton JC, Safe SH, van der Saag PT, van der Burg B and Gustafsson JA: Interaction of estrogenic chemicals and phytoestrogens with estrogen receptor $\beta$. Endocrinology 139, 4252 - 4263 (1998)

19 Anthony MS, Clarkson TB, Hughes CL Jr, Morgan TM and Burke GL: Soybean isoflavones improve cardiovascular risk factors without affecting the reproductive system of peripubertal rhesus monkeys. J Nutr 126, 43 - 50 (1996)

20 Honda H, Unemoto T and Kogo H: Different mechanisms for testosterone-induced relaxation of aorta between normotensive and spontaneously hypertensive rats. Hypertension 34, $1232-$ 1236 (1999)

21 Korenman SG, Stevens RH, Carpenter LA, Robb M, Niswender GD and Sherman BM: Estradiol radioimmunoassay without chromatography: procedure, validation and normal values. J Clin Endocrinol Metab 38, 718 - 720 (1974)

22 Taya K, Watanebe G and Sasamoto S: Radioimmunoassay for progesterone, testosterone and estradiol- $17 \beta$ using ${ }^{125}$ I-iodohistamine radioligands. Jpn J Anim Reprod 31, 186 - 197 (1985)

23 Miller VM and Vanhoutte PM: 17 $\beta$-Estradiol augments endothelium-dependent contractions to arachidonic acid in rabbit aorta. Am J Physiol 258, R1502 - R1507 (1990)

$24 \mathrm{Lu} \mathrm{LJ}$, Anderson KE, Grady JJ and Nagamani M: Effects of soya consumption for one month on steroid hormones in premenopausal women: implications for breast cancer risk reduction. Cancer Epidemiol Biomarkers Prev 5, 63 - 70 (1996)

25 Rahimian R, Laher I, Dube G and van Breemen C: Estrogen and selective estrogen receptor modulator LY117018 enhance release of nitric oxide in rat aorta. J Pharmacol Exp Ther 283, 116 - 122 (1997)

26 Miller VM and Vanhoutte PM: Progesterone and modulation of endothelium-dependent responses in canine coronary arteries. Am J Physiol 261, R1022 - R1027 (1991)

27 Mendelsohn ME and Karas RH: The protective effects of estrogen on the cardiovascular system. N Engl J Med 340, $1801-$ 1811 (1999)

28 Chen Z, Yuhanna IS, Galcheva-Gargova Z, Karas RH, Mendelsohn ME and Shaul PW: Estrogen receptor $\alpha$ mediates the nongenomic activation of endothelial nitric oxide synthase by estrogen. J Clin Invest 103, 401 - 406 (1999)

29 Mendelsohn ME: Nongenomic, estrogen receptor-mediated activation of endothelial nitric oxide synthase: How does it work? What does it mean? Circ Res 87, 956 - 960 (2000)

30 Walker HA, Dean TS, Sanders TA, Jackson G, Ritter JM and Chowienczyk PJ: The phytoestrogen genistein produces acute nitric oxide-dependent dilation of human forearm vasculature with similar potency to $17 \beta$-estradiol. Circulation 103, $258-$ 262 (2001)

31 MacRitchie AN, Jun SS, Chen Z, German Z, Yuhanna IS, Sherman TS and Shaul PW: Estrogen upregulates endothelial nitric oxide synthase gene expression in fetal pulmonary artery endothelium. Circ Res 81, 355 - 362 (1997)

32 Satake N, Shibata M and Shibata S: Endothelium- and cytochrome P-450-dependent relaxation induced by isoproterenol in rat aortic rings. Eur J Pharmacol 319, 37 - 41 (1997)

33 Laethem RM, Laethem CL and Koop DR: Purification and properties of a cytochrome $\mathrm{P} 450$ arachidonic acid epoxygenase 
from rabbit renal cortex. J Biol Chem 267, 5552 - 5559 (1992)

34 Imaoka S and Funae Y: The physiological role of P450-derived arachidonic acid metabolites. Folia Pharmacol Jpn (Nippon Yakurigaku Zasshi) 112, 23 - 31 (1998) (text in Japanese with English abstract)

35 Carroll MA, Garcia MP, Falck JR and Mcgiff JC: Cyclooxygenase dependency of the renovascular actions of cytochrome P450-derived arachidonate metabolites. J Pharmacol Exp Ther 260, 104 - 109 (1992)

36 Escalante B, Omata K, Sessa W, Lee S-G, Falck JR and Schwartzman ML: 20-Hydroxyeicosatetraenoic acid is an endothelium-dependent vasoconstrictor in rabbit arteries. Eur J Pharmacol 235, 1 - 7 (1993) 